\title{
Development of Korean Version of Developmental Coordination Disorder Questionnaire (DCDQ-K)
}

\author{
Joo Yeon Ko ${ }^{1}$, Wan Hee Lee ${ }^{2}$, Jee Woon Jung ${ }^{3}$, Young A Kim ${ }^{4}$ \\ 'Department of Physical Therapy, Daegu Health College, Daegu; ${ }^{2}$ Department of Physical Therapy, Shamyook University, Seoul; ${ }^{3}$ Noli Movement \\ Development Center, Seongnam; ${ }^{4}$ Department of Occupational Therapy, Inje university, Gimhae, Korea
}

Purpose: This study translated the developmental coordination disorder questionnaire'07 (DCDQ'07) into Korean and investigated the psychometric properties of the Korean DCDQ (DCDQ-K) using validation processes.

Methods: The subjects were 300 parents with typically developing children aged 5-15 years (162 girls and 138 boys, mean age 9.24 years, SD 2.59) across the country. To develop the Korean DCDO, a forward-backward-original author feedback-panel meeting-pilot study with parents was done. The internal consistency, test-retest reliability performed two weeks apart, content validity, discriminative validity, convergent validity, and constructive validity were examined with the pre-version of the DCDQ-K.

Results: Approximately $15.33 \%$ of the subjects were probably shown DCD using DCDQ-K. Significant differences in age and province were observed in the DCDQ-K total score. The reliabilities and validities were good in the DCDQ-K.

Conclusion: The DCDQ-K is a reasonable screening tool for DCD children.

Keywords: Developmental Coordination Disorder, Questionnaire, Korea, Motor Skill, DCDQ-K

\section{서 론}

발달성협응장애(developmental coordination disorder, $\mathrm{DCD})$ 는 운동기 술(motor skills)을 협응된 패턴으로 수행하고 학습하는 것이 어려워 학업 및 일상생활에 큰 지장을 끼쳐 물리치료 중재를 요하는 만성운 동장애이다.' 아동의 약 $6 \%$ 에서 발생하지만 이러한 운동장애는 의학 적 질환 또는 지적장애에서 비롯된 것은 아니다. 발달성협응장애는 취학시기가 되어 또래 활동과 참여에 필요한 활발한 신체활동이 요 구되면서 두드러진다. 대표적인 증상은 서툰 움직임, 사람 또는 물건 에 자주 부딪히고 넘어짐, 새로운 스포츠나 게임을 배우는 속도가 또 래보다 느림, 의자에 잘 앉아 있지 못하고 바닥으로 미끄러져 내려옴, 신발끈 묶기 어려움, 옷 뒤집어 입기, 알아보기 힘든 글씨체 등이다. 발 달성협응장애는 그 증상과 정도가 다양하여 대운동기술 또는 소운 동기술 어느 한 영역에만 문제가 있거나 두 영역 모두에서 어려움을 보이기도 하는데, 성장하면서 저절로 좋아지는 것이 아니라 성인기까 지 이어지는 영구적인 운동장애이다.3.4 아동기의 부족한 운동기술은 또래활동의 어려움과 잦은 갈등, 낮은 자존감, 분노 및 우울증, 비만

Received Dec 31, 2019 Revised Feb 6, 2020

Accepted Feb 24, 2020

Corresponding author Joo Yeon Ko

E-mail julie0202@dhc.ac.kr
위험6 등으로 사회 참여에 제한이 따르기 쉽다.7

남아 대 여아의 발생률은 2:1 정도이며, 만삭아(full-term baby)에 비 하여 32 주 이전에 출생한 조산아(preterm baby)에서 6.29배 높고, ${ }^{8}$ 32-36주에 출생한 조산아에서도 2 배나 높다. 주의력결핍과잉행동장 애, 언어에 기초한 학습장애, 단순 언어장애, 또는 읽기 장애 진단을 받은 아동의 약 $50 \%$ 에서 발달성협응장애가 동반된다. ${ }^{10}$ 발달성협응 장애의 진단은 DSM-5 (The diagnostic and statistical manual of mental disorders, fifth edition) 기준에 따른다. DSM-5에서 제시한 발달성협응 장애 진단기준은 1) 협응된 운동기술의 획득과 수행이 아이의 연령 과 지능수준에 비해 현저히 떨어진다; 2) 운동기술 결함으로 연령에 적합한 일상활동을 수행하는 것이 지속적으로 문제가 된다; 3) 증상 은 초기발달 시기에 시작된다; 4 ) 운동기술 결함이 지적장애(지적발 달성장애) 또는 시각 손상에 의한 것이 아니며 움직임 장애가 나타나 는 신경학적 상태(예: 뇌성마비, 근육병, 퇴행성 질환)에서 기인한 것 이 아니다." $\mathrm{DSM}-5$ 의 기준 A를 확인하기 위하여 반드시 표준화된 운 동 검사도구로 운동기능 평가를 해야한다.

Movement ABC-2 (movement assessment battery for children, 2nd 
edition)는 발달성협응장애를 진단하는 가장 대표적인 평가도구이지 만, ${ }^{12}$ 숙련된 평가자가 피험자 1명을 측정하는데 30-40분 정도 소요된 다는 점을 고려했을 때 시간적, 공간적 제약이 있다. 아동발달을 선별 (screening)하는 검사는 간단하며, 규준지향적(norm-referenced)이며, 비용이 비싸지 않고, 실시과정이 표준화되어야 하며, 객관적 절차에 따라 점수를 계산하고, 신뢰도와 타당도가 입증된 것이라야 한다. ${ }^{13}$ Developmental Coordination Disorder Questionnaire (DCDQ)는 2000 년도에 캐나다에서 처음 개발된 발달성협응장애 질문서로 2007년 DCDQ'07로 개정되었다. DCDQ'07은 만 5-15세 자녀를 둔 부모가 비 슷한 또래의 운동협응력과 비교하여 5점 척도로 점수를 주는 부모 보고식(parent-reported) 설문지로 일상생활과 밀접한 전반적인 운동 협응능력을 검사할 수 있다. 아동의 운동 발달에 관한 부모보고식 평 가는 그 신뢰도와 타당도가 높은 것으로 알려져 있다. ${ }^{14}$ 지난 20년 동 안 $\mathrm{DCDQ}$ 는 연구와 임상의 목적으로 발달성협응장애의 진단과정에 서 중요한 부분으로 사용되고 있으며 DSM-5 A기준을 충족하기 위 한 운동기능 검사에서 Movement ABC-2와 함께 사용할 수 있는 선별 목적의 검사도구이다. 현재 DCDQ 07 은 중국, ${ }^{15}$ 일본, ${ }^{16}$ 독일, ${ }^{17}$ 스페 인, ${ }^{18}$ 터키, ${ }^{19}$ 프랑스, ${ }^{20}$ 인도, ${ }^{21}$ 브라질 ${ }^{22}$ 등에서 이문화 간 적응(crossculturally adaptation)과정에 따른 번역 및 표준화를 거쳐 발달성협응 장애 아동을 선별검사하는데 사용되고 있다. ${ }^{23}$

국내의 경우 발달성협응장애 아동의 발생률에 대한 전문적인 통 계가 보고된 바는 없지만 조산아 발생률의 증가, 사회구조적 변화로 자녀에 대한 관심 증가, 그리고 유치원/학교 교육에서 신체활동 비중 의 증가 등으로 인해 이전에 비해 다양한 운동 발달상의 어려움으로 전문가를 찾는 사례가 크게 늘고 있다. 더욱이, 발달성협응장애의 평 가 도구와 관련된 연구도 거의 이루어지지 않은 실정이며 원래 영어 로 개발된 $\mathrm{DCDQ}$ 를 공식적으로 한글로 번역하여 표준화는 연구도 이루어지지 않았다.

DCDQ'07은 일상 활동과 밀접한 운동과제로 구성된 설문지로 학 교 갈 시기에 뚜렷해지는 발달성협응장애 아동을 선별하는데 활용 할 수 있으며 더 나아가 또래활동 및 학업에 필요한 물리치료 운동 중 재를 계획하는데도 사용할 수 있을 것이다. 본 연구에서는 DCDQ'07 의 한글화, 한글화된 $\mathrm{DCDQ} 07$ 의 신뢰도 및 타당도 조사의 과정을 거 쳐 한글화된 발달성협응장애 질문서(DCDQ-K)를 개발하고자 한다.

\section{연구 방법}

\section{1. 연구대상}

피험자는 서울, 경기도, 대구 그리고 부산 소재 일반 어린이 집/유치 원, 초등학교 그리고 중학교에 다니는 만 5-15세의 자녀를 둔 학부모 300 명이다. 피험자의 수는 기존의 연구를 근거 ${ }^{24}$ 로 아래와 같은 파워
계산식을 사용하여 구하였다.

sigma 1: 11.07점, sigma 2: 9.03점, Z_(1-alpha/2)=1.96, Z_(1-beta) $=0.84, \mathrm{D}=2.31$ 점

$$
n=\frac{\left(\sigma_{1}^{2}+\sigma_{2}^{2}\right) \times\left(z_{1-\alpha / 2}+z_{1-\beta}\right)^{2}}{D^{2}}
$$

피험자 모집은 아동의 운동협응능력 평가에 관하여 각 기관 홍보 및 설명을 통하여 해당 연령 아동 보호자의 자발적 참여를 통해 모집 하였으며 연구수행에 관하여 생명윤리심의위원회 승인과 시험에 참 여한 부모로부터 동의를 구하였다.

피험자 제외기준은 전반적 발달지연, 근육·골격계통질환, 신경·피 부계통질환, 다운증후군, 뇌성마비, 듀센형근이영양증, 자폐증, 외상 성뇌손상 등 의학적 질환에 의한 운동기능장애가 있는 자녀를 둔 부 모이다.

\section{2. 실험방법}

1) 측정도구

DCDQ'07은 부모의 관점에서 일상생활과 학업에 필요한 운동기술에 대한 자녀의 전반적 협응력(운동기술)을 설문지 형태로 평가하는 도 구이다. DCDQ'07은 만 5-15세 아동을 대상으로 3개의 요인(움직임 조절, 소운동기술/글씨 쓰기, 전신 협응력[대운동기술])에 대하여 공 던지기, 공 받기, 공 치기, 장애물 넘기, 달리기, 신체활동 계획, 빠르게 글씨 쓰기, 정확하게 글씨 쓰기, 힘 조절하기, 자르기, 스포츠 참여, 새 로운 기술 배우기, 일상생활의 능숙함, 조심성 정도 그리고 의자에 똑 바로 앉아 있기(피로 정도) 등 전반적인 운동능력을 평가할 수 있도록 15 개 항목으로 구성되어 있다.

각 항목은 5점 리커트척도로 '전혀 아니다는 1점, '약간 그렇다는 2 점, '보통이다는 3 점, '상당히 그렇다는 4 점, 그리고 '매우 그렇다는 5점 으로 총점은 15-75점 범위를 갖는다. DCDQ'07의 총점에 대하여 5-7.11세, 8-9.11세, 그리고 10-15세로 나누어 해석한다. 세 개의 연령군 별로 DCDQ'07 총점 15-46점, 15-55점, 15-57점에 해당하는 아동은 '발 달성협응장애 또는 의심(probably DCD)'으로 해석한다. DCDQ'07을 작성하는데 약 $10-15$ 분이 걸린다.

DCDQ'07의 내적일치도는 Chronbach's $\alpha=0.94$, 민감도 $85 \%$, 특이 도 $71 \%$ 이다. $\mathrm{DCDQ} 07$ 은 $\mathrm{MABC}-2$ 와 상관관계를 가지며, 발달성협응 장애의 유무에 대한 변별타당도가 입증되었으며, 요인분석에서 그 구성항목들이 일상생활과 학업의 맥락에서 운동기술을 측정해 주 는 것으로 나타났다.23

이 연구에서 사용한 질문서는 DSM-5 기준을 고려하여 준비되었 다. 기준 $\mathrm{A}$ 는 $\mathrm{DCDQ} 07$ 의 15 문항, 기준 $\mathrm{B}, \mathrm{C}$, 그리고 $\mathrm{D}$ 를 충족하기 위 하여 질문서에 의학적 질환 여부, 운동발달장애 여부, 그리고 지적장 애발달 여부 등을 확인하는 문항을 추가하여 사용하였다. 


\section{2) $\mathrm{DCDQ} 07$ 번역 절차 및 표준화}

평가도구 번역은 2017년 DCDQ'07의 원저자인 Brenda Wilson으로부 터 이메일 교환을 통한 한국판 DCDQ'07의 개발에 대한 정식 승인과 상호 간에 협약서를 작성하였다. DCDQ'07의 한글번역 과정은 원저자 가 보내준 '부모 보고식 척도의 이 문화 간의 적응 과정 가이드라인'에 따라 제 6 단계 ${ }^{25,26}$ 로 이루어진다. 제1단계, 번역자 2 명에 의한 DCDQ'07 의 한글 번역(forward translation), 제2단계, 한글로 번역된 각 DCDQ'07 의 통합 수정, 제 3 단계, 한글로 번역된 DCDQ'07 통합본의 영어로 역 번역(backward translation) 후 원저자와 내용 확인, 제4단계, 전문가로 구성된 위원회에서 번역-역 번역 내용 합의, 제 5 단계, 부모를 대상으로 한글화된 DCDQ'07의 초벌 질문서 파이럿 조사(pilot study), 제6단계, 한글화된 DCDQ'07의 신뢰도와타당도 검사 등이다.

신뢰도는 내적일치도와 검사-재검사신뢰도를 조사한다. 검사-재 검사신뢰도는 1 차 전자설문 후, 2 차 설문에 동의한 부모를 대상으로 2주 후에 실시한다. ${ }^{27}$ 타당도는 내용타당도, 변별타당도, 수렴타당도, 구성타당도 등을 조사한다.

\section{3) 자료분석}

각 요인 별 그리고 총점의 평균 및 표준편차를 확인하기 위하여 기술 통계를 구한다. 한글화된 DCDQ 각 항목 별 내적일치도(internal consistency)를 확인하기 위하여 Cronbach's $a,{ }^{28}$ 검사-재검사신뢰도(testretest reliability)는 intra-correlation coefficient (ICC, 급내상관계수)를 구한다. ${ }^{29-32}$ 내용타당도(content validity)는 한글화된 DCDQ의 15 개 문 항에 대한 내용의 적절성을 검증하는 것으로 각 문항의 적합성 정도 에 따라 1점 매우 부적합, 2점 부적합, 3점 보통, 4점 적합 그리고 5점 매우 적합 등으로 점수를 부여한 후 1 점은 $0.00,2$ 점은 $0.25,3$ 점은 0.50 , 4 점은 0.75 그리고 5점은 1.00 으로 할당하여 문항 별로 산술평균을 산정한다. 변별타당도(discriminative validity)를 알아보기 위하여 성 별 간의 차이는 independent t-test, 세 개의 연령군과 지역별 차이는 one-way ANOVA 검증 후 유의한 변수 간에 사후검증을 실시한다. 수 렴타당도(convergent validity)는 한글화된 DCDQ'07의 세 가지 요인인 움직임 조절, 소근육운동/글씨 쓰기 그리고 전신협응력 간의 Pearson's correlation coefficient (r)를 구하고, 구성타당도(constructive validity)는 confirmatory factor analysis (CFA)로 한글화된 DCDQ'07을 세 가지 요 인의 적합성을 평가한다. 통계분석은 SPSS 23.0 소프트웨어를 사용하 고 유의수준은 0.05 로 한다.

\section{결 과}

\section{DCDQ'07의 한글화 번역 과정}

제 1 단계 번역은 아동운동발달분야 전문 경험이 있는 물리치료사 2 명
이 담당하였고, 제 2 단계로 연구자와 각기 번역을 맡은 두 명의 물리 치료사가 함께 논의를 거쳐 한글 통합본을 완성하였다.

제 3 단계에서는 독일 출신의 한국어와 영어에 능통한 한국에 15 년 이상 거주한 대학교수가 영어로 다시 역 번역한 것을 원저자인 Brenda Wilson에게 전달하였다. 이에 대하여 Brenda Wilson으로부터 DCDQ'07이라는 용어 대신에 DCDQ로 사용할 것과 14 번 항목 역 번 역(The child is not clumsy, and doesn't often distribute other people (The child is careful and bumps into other objects)에 대하여 'please check to make sure that your Korean version has "does not bump into" (i.e., "The child is not clumsy, and doesn't often distribute other people (The child is careful and ${ }^{* *}$ does not** bump into other objects")'에 대한 피드백을 받 아 제 4 단계와 5 단계에서 수정 및 보완작업을 하였다. 이후로 DCDQ' 07 대신에 DCDQ라는 용어를 사용할 것이다.

제4단계에서는 아동물리치료사, 아동작업치료사, 초등학교 선생 님, 초등특수학교 선생님, 학부모로 구성된 전문집단회의에서 내용 타당도를 조사하여 1 차적으로 한글화된 $\mathrm{DCDQ}$ 를 완성하였다.

제 5 단계에서 30 명의 학부모를 대상으로 한 파일럿 조사결과를 정 리하여 점수체계 표현, 거리 표현, 표현 단어의 적합성, 추가 단어 삽 입 등의 작업을 실시하였다. 점수체계에서 수정 및 보완한 점은 '전혀 그렇지 않다'는 '전혀 아니다', '제법 그런 편이다'는 상당히 그렇다'로 수정하였다. 거리 표현은 2번 항목 '우리 아이는 $1.8-2.4 \mathrm{~m}$ 거리에서 던 지는 작은 공(예: 테니스 공)을 잡는다'에서 1명의 어머니가 $1.8-2.4 \mathrm{~m} ㅌ ㅓ ~$ 라는 거리가 측정하기 좀 어려운 것 같아 $1-2 \mathrm{~m}$ 로 하면 좋겠다는 의견 이 있었으나 원문에서 '1.8-2.4 m'로 분명히 명시되어 있어 원문의 내 용을 충실히 반영하였다. 표현 단어의 적합성은 14 번 문항: '부주의하 지 않다'에서 '조심성이 있다라는 긍정형 질문에 대한 요구가 있어 원 저자와 논의한 결과 반드시 'does not'의 형태로 번역해야 한다는 피드 백을 받아 반영하였다. 추가 단어 삽입은 ' 10 번 항목: Your child cuts out pictures and shapes accurately and easily'에서 가위 등의 도구를 명 시해주는 것이 좋다는 학부모들의 피드백을 원저자와 검토하여 최 종 개발될 한국 버전 DCDQ에서는 10 번 항목에 '가위'란 단어를 삽 입하여 '우리 아이는 가위로 그림과 도형을 정확하고 쉽게 자른다로 항목을수정하였다.

\section{2. 한글화된 $D C D Q$ 의 신뢰도 및 타당도 조사}

서울, 경기, 대전, 대구, 광주, 부산 등 주요 수도권과 지방에 거주하며 만 5-15세 자녀를 둔 부모 300명을 대상으로 2주 간격으로 ${ }^{27}$ 회에 걸 쳐 한글화된 $\mathrm{DCDQ}$ 의 전자설문조사를 실시하여 산출한 결과를 바 탕으로 DCDQ-K를 개발하였다(부록 1). 대상자의 일반적 특성은 Table 1 에서 알 수 있으며, 응답자를 대상으로 설문지 난이도를 조사한 결과 '이해하기 쉽다' 252 명(83.4\%), '보통이다' 45 명(14.9\%), '아니다' 3명 
(1\%)이었다.

\section{1) $\mathrm{DCDQ}-\mathrm{K}$ 점수 결과}

전국 주요 도시 및 지방에 거주하는 만 5-15세 자녀를 둔 부모를 대상 으로 한 DCDQ-K 조사에서 연령대별 점수는 Table 2에 나와 있으며, 세 개의 연령대 5-7.11세 116명, 8-9.11세 62명, 10-15세 122명에서 각기 12

\begin{tabular}{lc} 
Table 1. General characteristics of the subjects & $(\mathrm{N}=300)$ \\
\hline Variables & $9.24 \pm 2.59$ \\
\hline Age & \\
Gender & $162(54)$ \\
Girls & $138(46)$ \\
Boys & \\
Age bands (yr) & $116(38.7)$ \\
$5-7.11$ & $62(20.7)$ \\
8-9.11 & $122(40.7)$ \\
$10-15$ & \\
Provinces & $137(45.7)$ \\
Seoul/Gyeonggi & $55(18.3)$ \\
Daegu/Gyeongbuk & $75(25)$ \\
Busan & $17(5.7)$ \\
Daejeon/Chungcheong & $4(1.3)$ \\
Gwangju/Jeolla & $12(4)$ \\
Others & \\
Respondent & $281(93.7)$ \\
Mother & $19(6.3)$ \\
Father &
\end{tabular}

Unit: Mean \pm standard deviation or $\mathrm{N}(\%)$.
명(10.34\%), 15명(24.19\%), 그리고 19명(15.33\%), 300명 전체를 기준으로 46명(15.33\%)이 발달성협응장애 의심으로 선별조사 되었다(Figure 1).

\section{2) $\mathrm{DCDQ}-\mathrm{K}$ 신뢰도 및 타당도}

DCDQ-K의 내적일치도는 Cronbach's $\alpha=0.922$, 항목이 삭제된 경우 Cronbach's $\alpha=0.917-0.922$ 이었다. DCDQ-K의 검사-재검사신뢰도는 1 차 설문조사 후 재 설문조사에 응한 학부모 244 명을 대상으로 2주 후 에 진행한 설문결과에 따른 것으로 대체적으로 $\mathrm{ICC}=>0.7$ 으로 DCDQ-K가 신뢰할만한 안정성이 있음을 확인하였다(Table 3).

$\mathrm{DCDQ}$ 의 번역 과정 제 4 단계에서 조사한 번역 중인 $\mathrm{DCDQ}$ 의 내용 타당도는 소아물리치료사, 소아작업치료사, 초등학교교사, 특수학 교교사, 그리고 학부모를 대상으로 한 번역 내용의 적절성에 대한 조 사를 통해 내용 타당도 지수는 0.8 이상이었다.

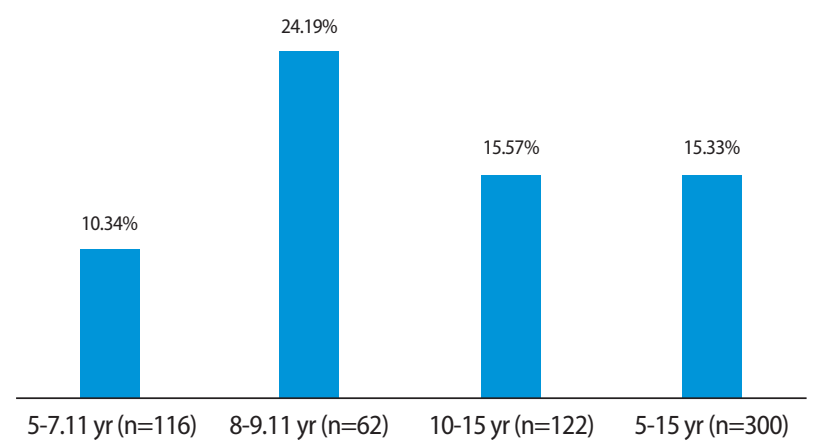

Figure 1. Percentage of children identified as probably DCD by DCDQ-K.

Table 2. DCDQ-K scores according to the age bands

\begin{tabular}{|c|c|c|c|c|c|}
\hline \multirow{2}{*}{ Age (yr) } & \multirow{2}{*}{ DCDQ-K } & \multicolumn{2}{|c|}{ 1st test $(N=300)$} & \multicolumn{2}{|c|}{ 2nd test $(N=244)$} \\
\hline & & $\mathrm{M} \pm \mathrm{SD}$ & Range (Min-Max) & $\mathrm{M} \pm \mathrm{SD}$ & Range (Min-Max) \\
\hline \multirow[t]{4}{*}{$5-7.11$} & Control during movement & $23.05 \pm 3.97$ & $11-30$ & $23.6 \pm 4.32$ & $10-30$ \\
\hline & Fine motor/handwriting & $16.97 \pm 3.12$ & $8-20$ & $17.08 \pm 3.32$ & $7-20$ \\
\hline & General coordination & $18.47 \pm 3.82$ & $7-25$ & $18.79 \pm 3.74$ & $8-25$ \\
\hline & Total & $58.49 \pm 9.86$ & $30-75$ & $59.47 \pm 10.14$ & $32-75$ \\
\hline \multirow[t]{4}{*}{$8-9.11$} & Control during movement & $24.56 \pm 3.50$ & $15-30$ & $24.11 \pm 4.11$ & $13-30$ \\
\hline & Fine motor/handwriting & $17.32 \pm 3.05$ & $8-20$ & $17.47 \pm 3.15$ & $7-20$ \\
\hline & General coordination & $19.55 \pm 3.35$ & $8-25$ & $19.05 \pm 3.82$ & $8-25$ \\
\hline & Total & $61.44 \pm 8.76$ & $31-75$ & $60.63 \pm 9.66$ & $28-75$ \\
\hline \multirow[t]{4}{*}{$10-15$} & Control during movement & $25.94 \pm 3.80$ & $15-30$ & $25.97 \pm 3.76$ & $16-30$ \\
\hline & Fine motor/handwriting & $18.37 \pm 2.25$ & $12-20$ & $18.53 \pm 2.21$ & $10-20$ \\
\hline & General coordination & $20.7 \pm 3.18$ & $14-25$ & $20.92 \pm 3.65$ & $9-25$ \\
\hline & Total & $65.02 \pm 8.09$ & $42-75$ & $65.43 \pm 8.21$ & $44-75$ \\
\hline \multirow[t]{4}{*}{$5-15$} & Control during movement & $24.54 \pm 4.04$ & $11-30$ & $24.68 \pm 4.19$ & $10-30$ \\
\hline & Fine motor/handwriting & $17.61 \pm 2.85$ & $8-20$ & $17.76 \pm 2.94$ & $7-20$ \\
\hline & General coordination & $19.60 \pm 3.60$ & $7-25$ & $19.75 \pm 3.85$ & $8-25$ \\
\hline & Total & $61.75 \pm 9.38$ & $30-75$ & $62.18 \pm 9.68$ & $28-75$ \\
\hline
\end{tabular}


Table 3. Test-retest reliability of the DCDQ-K

\begin{tabular}{clcc}
\hline Items & \multicolumn{1}{c}{ Contents } & ICC & $95 \%$ IC \\
\hline 1 & Throws ball accurately & 0.795 & $0.736-.0841$ \\
2 & Catches ball & 0.789 & $0.729-0.836$ \\
3 & Hits ball accurately & 0.802 & $0.746-0.846$ \\
4 & Jumps easily over obstacles & 0.536 & $0.438-0.661$ \\
5 & Runs as fast as, and in a similar way to & 0.784 & $0.722-0.832$ \\
6 & Plans motor activity & 0.720 & $0.640-0.782$ \\
7 & Writing fast & 0.791 & $0.731-0.837$ \\
8 & Writes legibly & 0.853 & $0.811-0.886$ \\
9 & Writing effort/tension is appropriate & 0.841 & $0.796-0.877$ \\
10 & Cuts pictures/shapes accurately & 0.819 & $0.767-0.859$ \\
11 & Like participating in sports/active games & 0.714 & $0.632-0.778$ \\
12 & Learns new motor tasks easily & 0.732 & $0.656-0.792$ \\
13 & Quick and competent & 0.790 & $0.729-0.837$ \\
14 & Not a 'bull in a china shop' & 0.721 & $0.642-0.784$ \\
15 & Does not fatigue/slouch/fall out of chair & 0.664 & $0.567-0.739$ \\
\hline
\end{tabular}

ICC: Intraclass correlation coefficient, Cl: Confidence interval.

변별타당도는 여아와 남아 간에 DCDQ-K의 차이는 소운동기술 요인에서만 차이를 보였다( $\mathrm{p}>0.05)$. 지역에 따른 차이는 특히 서울. 경기지역과 대구. 경북지역 간에 차이가 나타났으며 $(\mathrm{p}>0.05)$, 연령군 간에 차이를 보였다 $(\mathrm{p}>0.05)$.

수렴타당도는 DCDQ-K의 움직임 조절, 소운동기술/글씨 쓰기, 전 신 협응력, 그리고 총점 간의 상관성을 분석한 결과에서 총점과 움직 임 조절은 $r=0.915$, 총점과 전신 협응력은 $r=0.922$ 의 높은 수렴타당 도를 나타냈다.

구성타당도는 움직임 조절, 소운동기술/글씨 쓰기, 전신협응력 등 세 가지 요인을 구성하는 모든 항목들이 추정치가 0.5 이상으로 각 항목들이 측정해야 하는 바를 잘 측정하고 있는 것으로 나타났다 (Table 4).

\section{고 찰}

이 연구는 DSM-5 발달성협응장애 진단기준 A에 해당하는 세계적으 로 사용되는 DCDQ'07에 대하여 원저자와 한글 번역 및 표준화에 대 한 협약을 맺고 여섯 단계의 표준화과정을 거쳐 $\mathrm{DCDQ}-\mathrm{K}$ 를 개발하 는 것이다.

부모보고식 질문서 DCDQ-K 검사결과에 따라 아동 300 명 중에서 $15.33 \%$ 가 발달성협응장애 의심으로 확인되었다. 이 연구결과는 Tseng 등 ${ }^{15}$ 이 중국 아동 1,082명(나이 범위: 8-14.5세)을 대상으로 부모 설문을 통해 조사한 $11.2 \%$ 에 비해 낮고, Rivard 등 24 이 캐나다 온타리 오주 3,070명(평균 나이: 11.7세; 나이 범위: 8-15세)을 대상으로 조사한 $14.69 \%$ 에 비해 약간 높다. $\mathrm{DCDQ}$ 로 발달성협응장애의 위험이 있는
Table 4. DCDQ-K item factor analysis

$(N=300)$

\begin{tabular}{lccccc}
\hline DCDQ-K & Items & Estimate & SE & $\mathrm{Z}$ & $\mathrm{p}$ \\
\hline Control during movement & 1 & 0.83 & 0.0253 & 32.7 & $0.00^{*}$ \\
& 2 & 0.73 & 0.0361 & 20.3 & $0.00^{*}$ \\
& 3 & 0.70 & 0.0388 & 18.0 & $0.00^{*}$ \\
& 4 & 0.63 & 0.0421 & 14.9 & $0.00^{*}$ \\
& 5 & 0.69 & 0.0380 & 18.2 & $0.00^{*}$ \\
Fine motor/handwriting & 6 & 0.62 & 0.0426 & 14.6 & $0.00^{*}$ \\
& 7 & 0.73 & 0.0308 & 23.8 & $0.00^{*}$ \\
General coordination & 8 & 0.88 & 0.0195 & 44.9 & $0.00^{*}$ \\
& 9 & 0.87 & 0.0200 & 43.4 & $0.00^{*}$ \\
& 10 & 0.77 & 0.0275 & 28.1 & $0.00^{*}$ \\
& 11 & 0.57 & 0.0489 & 11.6 & $0.00^{*}$ \\
& 12 & 0.65 & 0.0433 & 15.1 & $0.00^{*}$ \\
& 13 & 0.78 & 0.0334 & 23.3 & $0.00^{*}$ \\
& 14 & 0.71 & 0.0400 & 18.1 & $0.00^{*}$ \\
& 15 & 0.68 & 0.0415 & 16.4 & $0.00^{*}$ \\
\hline
\end{tabular}

${ }^{*} p>0.05$

아동을 분류하는 기준 값은 문헌마다 약간의 차이가 있다. Tseng 등 15 은 10 백분위수를 기준으로 발달성협응장애 위험 아동을 선별하였 고, Rivard 등 24 은 5 백분위수 이하는 발달성협응장애, 6-15백분위수 는 발달성협응장애의 위험이 있는 것으로 분류하였다. 본 연구에서 는 원저자가 제시한 발달성협응장애 또는 의심으로 제시한 점수를를 기준으로 하였다.

DCDQ-K 평균 총점은 61.75점 이었다(Table 2). 이미 DCDQ가 표준 화된 나라들과 $\mathrm{DCDQ}$ 평균 총점을 비교하면 독일 버전(67명; 평균 나이: 4.41세, 나이 범위: 5-6.3세) 59.13점, ${ }^{17}$ 브라질 버전(707명; 평균 나 이: 8.22세) 나이 범위: 58.26 점22 보다 높았으며, 터키 버전(736명; 평균 나이: 9.27세, 나이 범위: 5.0-14.9세) 63.79점, ${ }^{19}$ 스페인 버전(460명; 평균 나이: 8.66세, 나이 범위: 6-12세) 64.64점18과 비교하여 낮았다. 이 결과 에 따라, 나라마다 사회문화적 양육방식이 다르므로 외국어로 된 평 가도구를 국내에서 사용할 때는 이 문화 간의 적응과정에 따라 평가 도구를 표준화해야함을 다시 한 번 확인할 수 있다.

DCDQ-K의 내적일치도는 Cronbach's $\alpha=0.922$, 항목이 삭제된 경 우 Cronbach's $\alpha=0.917-0.922$ 로 어떤 항목을 제거하더라도 다른 항목 들의 $\alpha$ 값이 증가하지 않아 15 개 항목 중 제거할 항목은 없다는 의미 이다. 또한 각 개별 항목 간에 수정된 항목 전체 상관관계는 0.5810.737 의 범위로 강한 내적일치도를 나타내었다. 이 연구결과는 Wilson 등 ${ }^{33}$ 의 오리지널 $\mathrm{DCDQ}$ 의 $\alpha=0.89$, 수정된 항목 전체 상관관계 $0.42-$ 0.67 과 유사하였으며, Yildirim 등 ${ }^{19}$ 의 터키 버전 DCDQ의 항목이 삭 제된 $\alpha=0.884-0.893$, 수정된 항목 전체 상관관계 0.496-0.624 보다 높 았다.

DCDQ-K의 검사-재검사신뢰도는 Yildirim 등 ${ }^{19}$ 의 터키 아동 150 명 
을 대상으로 한 검사-재검사신뢰도 ICC $=0.992-1.000$ 과 비교하여 낮 았으며 Ray-Kaese 등 20 의 스위스에서 불어를 사용하는 부모를 대상으 로 조사한 DCDQ-FE의 $\mathrm{ICC}=0.765-0.814$ 에 가까웠다. 이처럼 검사-재 검사신뢰도에 차이가 나는 것은 이 연구에서는 제 1 차와 2 차 설문조사 간격이 2주였지만, 터키 버전은 5일 간격, DCDQ-FE는 30일 간격이었 기 때문이다. 평가도구의 검사-재검사신뢰도 조사는 기억이 미치는 바이어스(bias)를 줄이기 위하여 일반적으로 2주간격으로 실시한다. ${ }^{27}$

남아와 여아 간의 협응력을 비교한 변별타당도 결과에서, 소운동 기술/글씨 쓰기에서 여아가 남아보다 점수가 높아 능숙한 것으로 나 타났다. 브라질, ${ }^{22}$ 스페인, ${ }^{18}$ 영어를 사용하는 캐나다 온타리오주에서 도 여아의 점수가 높았지만, ${ }^{24}$ 불어를 사용하는 캐나다 아동에서는 차이가 없었다. ${ }^{26}$ 일본 아동은 여아가 소운동기술/글씨 쓰기에서 남 아보다 능숙하였지만 움직임 조절에서는 남아가 여아에 비해 능숙하 였다. ${ }^{16}$ 이와 같이 문화에 따라 $\mathrm{DCDQ}$ 의 점수는 다르게 나타나 각 나 라의 문화에 맞게 개발한 $\mathrm{DCDQ}$ 를 사용하는 것이 타당한 것으로 보 여진다. 지역 간에 $\mathrm{DCDQ}-\mathrm{K}$ 의 세 가지 요인, 총점을 비교한 변별타당 도 결과에서, 서울. 경기지역의 결과가 다른 지역에 비해 높았다. 서 울. 경기지역의 피험자 수가 전체의 $45.7 \%$ 로 그 비율이 월등히 높았던 것이 영향을 미쳤을 것으로 여겨진다(Table 1). 연령군 별 DCDQ-K 점 수를 비교한 변별타당도 결과에서, 연령대가 높아질수록 움직임 조 절, 소운동기술/글씨 쓰기, 전신 협응력, $\mathrm{DCDQ}-\mathrm{K}$ 총점의 점수가 높 아졌으며 5-7.11세와 10-15세 간에는 연구대상자의 수를 고려하더라 도 뚜렷한 차이가 있었다.

$\mathrm{DCDQ}-\mathrm{K}$ 의 요인 별 상관관계를 통해 확인한 수렴타당도는 움직 임 조절, 전신 협응력 요인에서 $r=0.915,0.922$ 이었다. 공 던지기, 공 잡 기, 공 치기, 점프하기, 달리기, 운동계획 등 1번-6번 항목으로 구성된 움직임 조절 요인과 스포츠 즐기기, 새로운 운동기술 배우기, 민첩하 고 능숙하게 움직이기, 조심성 있게 움직이기, 잘 앉아 있기 등의 11 번-15번 항목으로 구성된 전신협응력은 DCDQ-K 총점과 큰 연관성 을 갖는 것으로 확인되었다.

$\mathrm{DCDQ}-\mathrm{K}$ 의 구성타당도는 모든 항목들이 추정치가 0.5 이상으로 $\mathrm{DCDQ}-\mathrm{K}$ 의 총점은 아동의 전체적인 운동 기능에 대한 정보를 그리 고 움직임 조절, 소운동기술/글씨 쓰기, 전신 협응력(대운동기술) 같 은 세 가지 요인은 각기 특정 운동기능에 대한 정보를 알려주는 것으 로 보인다. 이 연구결과는 Tseng 등디이 개발한 DCDQ 중국 버전의 결 과와 유사하다.

연구의 제한점은 첫째, 본 연구에서는 8-9.11세 아동의 수가 상대적 으로 적어 다른 두 연령대와 비교하는데 제한이 있다. 발달성협응장 애는 8 세 이후에 더욱 뚜렷이 나타나는데 그 이유는 달리기, 점프, 민 첩성, 속도 등이 요구되는 학교, 또래, 스포츠활동에 스스로 참여해 야 하는 시기이기 때문이다. 둘째, 발달성협응장애를 진단하기 위하
여 부모 보고식 DCDQ-K와 함께 MovementABC-2로 아동의 실제 협 응력을 측정하여 비교하지 못하였다.

출생 이후 대략 취학 전까지 걷기, 달리기, 계단, 한 발 서기, 점프, 깡 충 뛰기, 줄넘기 등의 이동성과 공 차기, 공 받기, 공 던지기 등의 공 다 루기 기술이 발달한다. 개인은 이 같은 기본운동기술을 응용, 확장하 여 평생에 걸쳐 필요한 활동과 스포츠에 참여한다. 물론, 이미 형성된 기본 운동기술은 크게 달라지지 않고, 근력, 지구력, 협응력 등에 변화 가 생긴다. 특히, 협응력은 일상에 필요한 기본운동기술을 효율적으 로 사용하는 능력으로 아이들의 학업 및 사회 참여의 기초가 된다. 발달성협응장애는 만성운동장애로 사회. 경제적 비용 손실 측면에 서 물리치료사의 전문적인 검사, 평가, 중재, 모니터링이 필요하며 이 를 위하여 표준화된 평가도구를 사용해야한다. ${ }^{34}$ 표준 번역과정을 거 쳐 신뢰도와 타당도가 입증된 DCDQ-K는 지역사회 및 임상에서 발 달성협응장애 아동을 선별할 수 있는 유용한 검사도구이다.

향후 우리나라 주요 도시의 초등학생을 대상으로 발달성협응장애 질문서의 전수조사를 실시하여 아이들의 기본운동능력을 파악하 는데 활용할 수 있을 것이며, DCDQ-K는 아동의 일상 활동과 밀접한 운동기술로 구성된 생태학적(ecological) 검사도구로 부모 중심(parent-centered), 놀이활동 중심(play-oriented)의 중재프로그램의 계획 및 개발에 사용될 수 있을 것이다.

\section{ACKNOWLEDGEMENTS}

이 논문은 2018 년 대한민국 교육부와 한국연구재단의 지원을 받아 수행된 연구임(NRF-2018S1A5A2A01033095).

\section{REFERENCES}

1. Summers J, Larkin D, Dewey D. Activities of daily living in children with developmental coordination disorder: dressing, personal hygiene, and eating skills. Hum Mov Sci. 2008;27:215-29.

2. Schoemaker MM, Flapper B, Verheij NP et al. Evaluation of the developmental coordination disorder questionnaire as a screening instrument. Dev Med Child Neurol. 2006;48;668-73.

3. Magalhaes LC, Missiuna CM, Wong S. Terminology used in research reports of developmental coordination disorder. Dev Med Child Neurol. 2006;48:937-41.

4. Sugden D. Current approaches to intervention in children with developmental coordination disorder. Dev Med Child Neurol. 2007;49(6):46771.

5. Missiuna C, Moll S, King S et al. A trajectory of troubles: parents' impressions of the impact of developmental coordination disorder. Phys Occup Ther Pediatr. 2007;27:81-101.

6. Cairney J, Hay J, Veldhuizen S et al. Trajectories of relative weight and waist circumference among children with and without developmental 
coordination disorder. CMAJ. 2010;182:1167-72.

7. Wilcox MJ, Woods J. Participation as a basis for developing early intervention outcomes. Lang Speech Hear Serv Sch. 2011;42:365-78.

8. Edwards J, Berube M, Erlandson K et al. Developmental coordination disorder in school-aged children born very term and/or at very low birth weight: a systematic review. J Dev Behav Pediatr. 2011;32:678-87.

9. Zhu JL, Olsen J, Olesen AW. Risk for developmental coordination disorder correlates with gestational age at birth. Paediatr Perinat Epidemiol. 2012;26:572-7.

10. Zwicker JG, Missiuna C, Boyd LA. Neural correlates of developmental coordination disorder: a review of hypotheses. J Child Neurol. 2009;24: 1273-81.

11. Diagnostic and statistical manual of mental disorders. 4 th ed, Text revision. Washington, DC: American Psychiatric Association, 2000.

12. Rosenblum $S$. The developmental and standardization of the children activity scales (ChAS-P/T) for the early identification of children with developmental coordination disorders. Child Care Health Dev. 2006;32(6):619-32.

13. Nancy AM, Robert ES. Mainstreaming students with mild handicaps: academic and social outcomes. Review of Educational Research. 1983;54(4):519-69.

14. Kwon HS, Son SM. Research on the quality of life of the parents by functions, activities, participation, and environmental factors of children with cerebral palsy using ICF-CY Checklist. J Kor Phys Ther. 2018;30(1): 35-40.

15. Tseng MH, Fu C, Wilson BN et al. Psychometric properties of a Chinese version of the developmental coordination disorder questionnaire in community-based children. Res Dev Disabil. 2010;31(1):33-45.

16. Hashimoto R, Sueda K, Yagyu K. Development of a movement questionnaire adapted for Japanese culture for elementary school children. Brain Dev. 2019;S0387-7604(19):30217-7.

17. Kennedy-Behr A, Wilson BN, Rodger S et al. Cross-cultural adaptation of the developmental coordination disorder questionnaire 2007 for German-speaking countries: DCDQ-G. Neuropediatrics. 2013;44(5): 245-51.

18. Delgado-Lobete L, Santos-Del-Riego S, Pertega-Diaz S et al. Prevalence of suspected developmental coordination disorder and associated factors in Spanish classrooms. Res Dev Disabil. 2019;86:31-40.

19. Yildirim CK, Altunalan T, Acar G. Cross-cultural adaptation of the developmental coordination disorder questionnaire in Turkish children. Percept Mot Skills. 2019;126(1):40-9.

20. Ray-Kaeser S, Thommen E, Martini R, et al. Psychometric assessment of the French European developmental coordination disorder questionnaire (DCDQ-FE). PloS One. 2019;14(5):e0217280.
21. Patel P, Gabbard C. Adaptation and preliminary testing of the developmental coordination disorder questionnaire (DCDQ) for children in India. Phys Occup Ther Pediatr. 2017;37(2):170-82.

22. Ferreira L, Gabbard C, Vieira JL et al. Associations between the developmental coordination disorder questionnaire-brazilian version (DCDQBR) and motor competence in school-age children. Phys Occup Ther. Pediatr. 2019;23:1-13.

23. Wilson BN, Kaplan BJ, Crawford SG et al. Reliability and validity of a parent questionnaire on childhood motor skills. Am J Occup Ther. 2000;54:484-93.

24. Rivard L, Missiuna C, McCauley D et al. Descriptive and factor analysis of the developmental coordination disorder questionnaire (DCDQ'07) in a population-based sample of children with and without developmental coordination disorder. Child Care Health Dev. 2014;40(1):42-9.

25. Beaton DE, Bombardier C, Guillemin F. Guidelines for the process of cross-cultural adaptation of self-report measures. Spine. 2000;25:318691.

26. Martini R, St-Pierre MF, Wilson BN. French Canadian cross-cultural adaptation of the developmental coordination disorder questionnaire' 07: DCDQ-FC. Can J Occup Ther. 2011;78(5):318-27.

27. Ko JY, Jung JW. Reliability and concurrent validity of Korean version of the trunk control measurement scale (K-TCMS) for children with cerebral palsy. J Kor Phys Ther. 2017;29(1):16-26.

28. Kim GW, Lee CS, Lee K. Study of work-related musculoskeletal pain and health-related quality of life among hospital. J Kor Phys Ther. 2019; 31(5):304-10.

29. Ha SM, Jeon IC. Reliability and validity of measurement using smart phone-based goniometer on pelvic tilting angle in standing and sitting position. J Kor Phys Ther. 2019;31(1):35-9.

30. Jang YJ, Lee JH, Oh JL et al. An analysis of the reliability and validity of a Korean version of the mobility and gait assessment tools for patients with stroke. J Kor Phys Ther. 2018;30(1):29-34.

31. Jeon IC. Comparisons of test-retest reliability of strength measurement of gluteus medius strength between break and make test in subjects with pelvic drop. J Kor Phys Ther. 2019;31(3):147-50.

32. Song JM, Lee HJ. Korean cultural adaptation of WHODAS 2.0 (36-Item Version): reliability and linking to ICF. J Kor Phys Ther. 2018;30(6):24655.

33. Wilson BN, Crawford SG, Green D et al. Psychometric properties of the revised developmental coordination disorder questionnaire. Phys Occup Ther Pediatr. 2009;29(2):182-202.

34. Lee HJ, Song JM. Development of the Korean version of ICF e-Learning tool. J Kor Phys Ther. 2019;31(2):88-93. 
부록 1. 한국판발달성협응장애질문서( $\mathrm{DCDQ}-\mathrm{K})$

\begin{tabular}{|c|c|c|c|c|c|}
\hline 문 항 & $\begin{array}{c}\text { 전혀 } \\
\text { 아니다 } \\
\text { (1) }\end{array}$ & $\begin{array}{c}\text { 약간 } \\
\text { 그렇다 } \\
\text { (2) }\end{array}$ & $\begin{array}{c}\text { 보통 } \\
\text { 이다 } \\
\text { (3) }\end{array}$ & $\begin{array}{c}\text { 상당히 } \\
\text { 그렇다 } \\
\text { (4) }\end{array}$ & $\begin{array}{c}\text { 매우 } \\
\text { 그렇다 } \\
\text { (5) }\end{array}$ \\
\hline 1. 우리 아이는 공을 정확하게 잘 던진다. & & & & & \\
\hline 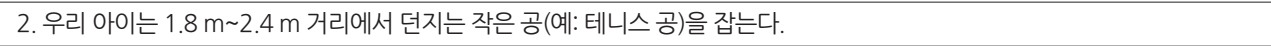 & & & & & \\
\hline 3. 우리 아이는 라켓 또는 방망이로 날라 오는 공을 정확히 맞힌다. & & & & & \\
\hline 4. 우리 아이는 공원이나 놀이터 바닥에 있는 물건이나 턱을 쉽게 넘어 다닌다. & & & & & \\
\hline 5. 우리 아이는 성별과 나이가 같은 또래와 같은 속도와 모습으로 달릴 수 있다. & & & & & \\
\hline 6. 우리 아이는 종이 판지나 쿠션 쌓기, 놀이터 놀이, 블록(점토)로 집 또는 모형 만들기 같은 운동 활동을 자연스럽게 수행한다. & & & & & \\
\hline 7. 우리 아이는 교실에서 색칠하기, 글쓰기, 그림 그리기 등을 다른 아이들과 비슷한 속도로 한다. & & & & & \\
\hline $\begin{array}{l}\text { 8. 우리 아이는 글자, 숫자, 단어 등을 알아볼 수 있게 정확하고 또렷하게 쓴다. 아이가 아직 글자 쓰기를 못한다면 색칠과 그리기를 } \\
\text { 부모가 알아볼 수 있는 형태로 한다. }\end{array}$ & & & & & \\
\hline $\begin{array}{l}\text { 9. 우리 아이는 색칠하기, 글씨쓰기, 또는 그림을 그릴 때 힘 조절을 잘 한다(예: 연필을 쥐는 힘이 너무 약하거나 세지 않으며, 글씨 } \\
\text { 체가 너무 진하거나 흐리지 않다). }\end{array}$ & & & & & \\
\hline 10. 우리 아이는 가위로 그림과 도형을 정확하고 쉽게 자른다. & & & & & \\
\hline 11. 우리 아이는 다양한 움직임(운동기술)이 요구되는 스포츠 또는 활동적인 게임에 참여하기를 좋아 한다. & & & & & \\
\hline 12. 우리 아이는 새로운 운동(예: 수영, 인라인 스케이트)을 쉽게 배우며 또래보다 시간이 더 많이 걸리거나 따로 연습이 필요하지 않다. & & & & & \\
\hline 13. 우리 아이는 물건 정돈, 신발 신기, 신발 끈 묶기, 옷 입기 등을 빠르고 능숙하게 한다. & & & & & \\
\hline 14. 우리 아이는 조심성 있게 움직인다(예: 좁은 실내에서 움직임이 서툴러 물건을 치고 다니거나 주변 사물에 부딪히지 않는다). & & & & & \\
\hline $\begin{array}{l}\text { 15. 우리 아이는 의자에 오래 동안 앉아있어야 할 때, 바른 자세로 잘 앉아 있는다(즉, 쉽게 피곤해하거나 자세가 구부정해지거나 의 } \\
\text { 자에서 내려오려 하지 않는다). }\end{array}$ & & & & & \\
\hline
\end{tabular}

